\title{
Hacer la ley. Legisladores y técnicos. La Cámara de Diputados entre 1932 y 1943
}

\section{(4) Ana Virginia Persello}

Facultad de Humanidades y Artes, Universidad Nacional de Rosario. Consejo de Investigaciones de la Universidad Nacional de Rosario, Argentina. Correo electrónico: vpersello@gmail.com

Artículo recibido: 24 de mayo de 2018. Aprobación final: 13 de noviembre de 2018.

\section{Resumen $^{1}$}

Debilidad, ineficacia, ineficiencia, abandono de sus funciones de control e inercia legislativa, constituyeron las principales críticas al parlamento a lo largo de su historia. El objetivo de este texto es confrontar las impugnaciones que se acumularon en torno a la eficacia del Congreso entre 1932 y 1943 y ponerlas en diálogo con el modo en que la Cámara de Diputados se hizo cargo de ellas a través de las propuestas abortadas y sancionadas para regular su funcionamiento interno; respuestas parciales y fragmentarias al problema nunca resuelto de la representación.

Palabras clave: Parlamento, Representación, Eficacia, Reglamento.

Making the Law. Lawmakers and technicians. The Chamber of Deputies between 1932 and 1943

\begin{abstract}
Weaknesses, ineffectiveness, inefficiency, lack of control and legislative inertia, have been the most criticized issues of parliamentary functioning throughout history. This article focuses on the Argentine parliament branch performance between 1932 and 1943. It confronts the accumulated challenges around the effectiveness of the Congress and put them in dialogue with the way in which the
\end{abstract}


Chamber of Deputies took charge of them through the diverse proposals (rejected or not) destined to regulate its internal functioning.

Keywords: Parliament, Representation, Effectiveness, Regulations.

\section{Introducción}

Debilidad, ineficacia, ineficiencia, abandono de sus funciones de control e inercia legislativa constituyeron las principales críticas al parlamento a lo largo de su historia. El objetivo de este texto es confrontar las impugnaciones que se acumularon en torno a la labor del Congreso entre 1932 y 1943 y ponerlas en diálogo con el modo en que la Cámara de Diputados se hizo cargo de ellas a través de las decisiones en torno a la incorporación de sus miembros y las propuestas abortadas y sancionadas para regular su funcionamiento interno.

Hace ya varias décadas que la historiografía se hizo cargo de sacar a los años 1930 del lugar en que se los había colocado en los '60, cuando el imperativo de releer al peronismo los pensó como una transición entre dos proyectos nacional-populares. La denuncia del fraude, la corrupción y la exclusión dominaron la interpretación. De la conjunción del rescate de archivos inexplorados y nuevas miradas encuadradas en la renovación de la historia política surgió su singularidad y su inscripción en una crisis que excedía ampliamente las fronteras nacionales. La recuperación de la incertidumbre, los tanteos, la reorientación de estrategias, la redefinición de las teorías que sustentaban la relación entre la sociedad y el estado, inscriptas en lo que Halperin llama "la tormenta del mundo" (Halperin Donghi, 2003), posibilitó la diagramación de un escenario mucho más complejo (Cattaruzza, 2001).

En ese escenario, ya abierto por la guerra, se puso en cuestión el liberalismo, la democracia y la asociación entre ambos; el rol del estado, los principios de legitimidad del poder, la representación e involucró la forma concreta en que las administraciones radicales habían resuelto el ingreso a la democracia de partidos. El diagnóstico, que se centró en el imperio de la demagogia, el ejecutivismo, la voluntad popular sobre la ley y sobre el fortalecimiento de las instituciones derivó en la impugnación del gobierno -el problema era Yrigoyen- o del sistema -la democracia no era el mejor régimen posible-. El golpe de septiembre dio cuenta de ambas perspectivas y las propuestas -ambiguas e inciertas- se concretaron en restaurar o reformar (Devoto, 2005; Persello, 2015). Según el ministro del Interior del gobierno provisional, M. Sánchez Sorondo, la "revolución" se quedó a medio camino porque el presidente interpretó que si bien el pueblo se había pronunciado contra un sistema aspiraba a que la reconstrucción se realizara respetando la estructura institucional. ${ }^{2}$ Lo cierto es que no se reformó la constitución para posibilitar que la institución de una segunda cámara incorporara los intereses 
colectivos, tal como los nacionalistas y el propio Uriburu proponían, aunque tampoco se saldó el debate acerca de la legitimidad del poder y la representación.

Los gobiernos civiles del período hicieron profesión de fe democrática, a la par que transgredieron los principios mismos que la sustentaban. El fraude fue alternativamente negado o asumido, o supuso un modo diferente de pensar el mecanismo electoral (De Privitellio, 198-213) y legitimidad y representación adquirieron nuevos fundamentos. Por otro lado, las transformaciones en la economía y las finanzas -regulación, control de cambios, nuevos impuestos-, se diagramaron y ejecutaron a través de comisiones consultivas que reunían a funcionarios, técnicos y representantes de intereses sectoriales y cuya creación se justificó con el argumento de que el sistema democrático de gobierno no poseía, hasta ese momento, medios institucionalizados de participación de los hombres de ideas y de experiencia, necesarios para encontrar las soluciones que la situación exigía.

La institución parlamentaria había sido fuertemente cuestionada en la etapa previa por el predominio de las pujas entre partidos y la inercia legislativa, producto, para la oposición al gobierno radical, del lugar que Yrigoyen le reservaba y de la confusión entre gobierno y partido y para el oficialismo, de la obstrucción opositora (Persello, 2004). A estos argumentos se sumaban otros del orden de la propia dinámica del trabajo parlamentario que perdurarán en los años ' 30: las sesiones preparatorias insumían demasiado tiempo; los legisladores descuidaban sus funciones durante la mayor parte del período, no se reunían con la debida asiduidad, dedicaban sesiones enteras a recriminarse mutuamente por causas banderizas y concentraban en los últimos días de septiembre los esfuerzos que debieron hacer durante los cinco meses que duraba el período ordinario de sesiones. Se sesionaba poco, por tiempos breves, se interrumpía el quórum con mucha frecuencia y se acudía escasamente a las comisiones que eran apenas antesalas o pasillos de tránsito. ${ }^{3}$ La novedad era que la incertidumbre se extendía a la evaluación de las posibilidades de los partidos y el parlamento para encontrar o, por lo menos acompañar, la salida de la crisis.

El Congreso es un espacio escasamente considerado por la historiografía argentina y sobre los años '30, en particular no ha sido objeto de estudios sistemáticos. El libro pionero de Darío Cantón (1966), que traza un perfil de los parlamentarios para dar respuesta a la inestabilidad política argentina, en un contexto, según propone, de avance del proceso de democratización, excluye la década del '30, a la que caracteriza como un momento de regresión, un interregno en el que dominó el fraude. Para la misma época, Alberto Ciria (1975, 1era. ed. 1964) fue uno de los primeros en ocuparse de la «crisis del parlamento» y también se la atribuyó al fraude, aunque incorporó además la estructura y organización de los partidos, el peso de las políticas intervencionistas diagramadas por el Poder Ejecutivo y de los "factores de poder" -Fuerzas Armadas, Iglesia, grupos económicos- como parte de la explicación. Aún en los años '80, cuando el imperativo de la democratización impulsó nuevas reflexiones sobre 
las instituciones en general, y sobre el parlamento en particular, ${ }^{4}$ para la historia siguió siendo un área de vacancia, exceptuando excelentes trabajos como el de Marcela Ferrari (2008) que reconstruye los elencos de representantes a través del seguimiento de trayectorias individuales para dar cuenta del proceso de profesionalización en los inicios de la democracia de partidos y el texto de Tulio Halperin Donghi (2004), La república imposible, que es imprescindible para dar cuenta, entre otras muchas cuestiones, de los dilemas de las élites dirigentes en relación al fraude.

En este caso, elegimos como vía de entrada, entre otras muchas posibles, recuperar los intentos de redefinición de las reglas que regían el trabajo de la cámara de diputados, no con la intención de reconstruir su dinámica ni evaluar resultados, sino de dar cuenta de un debate sobre su propia labor que el parlamento asumió como respuesta a las impugnaciones recurrentemente esgrimidas por la prensa, por la literatura política y por los políticos; debate donde se pone en juego la cuestión de la representación.

Una serie de textos más o menos recientes abordan los reglamentos que regían el trabajo de las legislaturas provinciales y su puesta en práctica para mostrar la importancia de la norma, su interpretación en el recinto, sus silencios, el aprovechamiento de sus espacios vacíos, sus transgresiones (Lanteri y Nanni, 2016; Garino, 2017). Y para la última década del siglo XIX y las primeras del XX, Moira MacKinnon (2017), en un análisis comparado del parlamento chileno y del argentino en torno a la legislación laboral, cuyo objetivo es medir representatividad y eficacia, también recurre al análisis de los reglamentos para mostrar que en el caso argentino son flexibles, se adaptan ad hoc y existen pocos mecanismos para zanjar los desacuerdos.

El texto está estructurado en dos partes. La primera sigue el itinerario de las decisiones sobre la incorporación de los miembros de la cámara. El examen de los diplomas por una comisión de poderes y su discusión en sesiones preparatorias insumía demasiado tiempo, daba lugar a arbitrariedades y le impedía a la cámara legislar. La mayoría compartía el argumento y la práctica impuso la incorporación automática de los miembros en 1932 aunque la sanción de la norma llegó recién en 1935, por razones diferentes a las expuestas. Los radicales habían levantado la abstención, se imponía el fraude y la postergación de la discusión de los diplomas a sesiones ordinarias permitía que los impugnados votasen. La segunda parte recupera las propuestas abortadas y las sancionadas para resolver problemas asociados a la dinámica parlamentaria y a la técnica legislativa que "encubren" una pregunta sobre la representación. La articulación entre ambas remite al problema de la eficacia que dependía, en los argumentos desplegados en la coyuntura, de anteponer la legislación al "debate político", y está atravesado, por un lado, por la certeza de los elencos gobernantes de que el fraude era legítimo en la medida en que excluía a los incapaces y por otro, por la pregunta

4 Una recopilación de los estudios sobre el parlamento realizados por la ciencia política y la sociología en Ortiz de Rozas (2017). 
sobre la capacidad de un parlamento formado únicamente por miembros de los partidos políticos para conocer sobre todas las materias sobre las que se hacía necesario legislar.

La democracia como régimen y el sufragio como principio de legitimidad no estaban en cuestión. El fraude remitía a la idea de que el gobierno debe ser ejercido por los "mejores". El presidente Justo, en el último mensaje al Congreso antes de dejar la presidencia, fue claro en ese sentido, el desempeño de los legisladores importaba más que haber sido seleccionados en "comicios intachables".

\footnotetext{
Olvidamos a menudo que no basta adaptar las formas democráticas para vivir la verdadera democracia. Es necesario compenetrarse de su contenido, de su sentido íntimo, y no atenerse sólo al mero cumplimiento de fórmulas que no tienen sino valor secundario. Ella es espíritu y no simple exterioridad. No basta haber surgido de comicios intachables para ser un exponente de alta democracia, verdad demostrada por dolorosas experiencias. La democracia debe ser juzgada, aparte de la pureza de los títulos de los representantes, por la forma en que éstos se desempeñan y por la acción que desarrollan a favor del pueblo. ${ }^{5}$
}

El debate sobre la necesidad de incorporar la técnica y los intereses al parlamento responde a una "aprehensión ampliada de la representación política", que viene a sumar una forma complementaria a la legitimidad surgida del sufragio universal, pero no a reemplazarla (Rosanvallon, 2004). El supuesto que vertebra estas notas es que el fraude vino a sumarse, coyunturalmente, e impulsado por la percepción de que el número había avasallado a la razón -aunque se mantuviera la irreversibilidad del sufragio universal como principio de legitimidad del podera cuestionamientos que involucraban a la institución parlamentaria a partir de la imposibilidad de dar respuestas acabadas al problema de la representación.

\section{El fraude}

\section{La incorporación automática}

En 1932, la Cámara de Diputados, a partir de un proyecto de resolución, reconoció la validez de los diplomas de todos sus miembros, aun con el voto en contra de la oposición que se resistía a convalidar el fraude perpetrado en la provincia de Buenos Aires. En caso de presentarse alguna impugnación se discutiría en sesiones ordinarias.

José N. Matienzo era uno de los tantos que venía bregando desde hacía tiempo por la supresión del examen de los diplomas en sesiones preparatorias, trámite que consideraba arbitrario, impuesto por la práctica y que demoraba innecesariamente la constitución de las cámaras. A poco de producido el golpe, en Remedios contra el gobierno personal, sostuvo un argumento que no era nuevo: las cámaras

5 (15 de mayo de 1937). Al inaugurar el 74operíodo legislativo el general Justo leyó ayer su último mensaje. La Nación, Buenos Aires, p. 1. 
se atribuían "errónea o maliciosamente" el derecho de aprobar o desaprobar la incorporación de sus miembros, en contra de la doctrina consagrada en las costumbres parlamentarias de Inglaterra y Estados Unidos, expuesta por los tratadistas de derecho parlamentario y seguida en la Argentina:

\begin{abstract}
los senadores y diputados electos prestarán el juramento prescripto en el artículo 59 de la Constitución, sin más requisito que la exhibición de su diploma, expedido por funcionario competente, salvo que algún miembro de la Cámara les niegue alguna de las calidades requeridas por la Constitución para ser elegidos, en cuyo caso se resolverá previamente la cuestión conforme al reglamento de la cámara respectiva. ${ }^{6}$
\end{abstract}

Y en 1932, desde su banca en el Senado presentó un proyecto ${ }^{7}$ que eliminaba el juicio previo de los diplomas y que venía así a cristalizar lo que la práctica había instalado. Se basaba en que el artículo 56 de la Constitución que establecía que cada Cámara era juez de la elección, derechos y títulos de sus miembros no había sido reglamentado, y el sistema ponía en manos de la mayoría la posibilidad de restringir la libertad de sufragio o alterar su resultado. Sin embargo, a pesar de tener consenso, no se sancionó. La discusión se centró en un artículo, el 5o, que establecía que dentro de los 30 días de proclamada la elección, cualquier ciudadano domiciliado en la provincia podía impugnarla ante el juez federal correspondiente. La demanda de algunos legisladores era restringir su alcance, de otro modo, los diplomas podían ser "juguete de la politiquería", y lejos de suprimir la injerencia de la política se arrastraría a diputados y senadores a "toda clase de probanzas y discusiones".

En 1934 se repitió el procedimiento. La Comisión de Poderes presentó despacho distrito por distrito y, con mínimas objeciones, todos los diputados fueron incorporados y la Cámara quedó constituida. Y se reiteró el argumento de que de ese modo se evitaba ventilar en el recinto las pasiones y el encono que atravesaban los debates políticos que insumían el tiempo de legislar. ${ }^{10}$ Había que demostrar que "el Parlamento sigue siendo todavía un organismo de gobierno útil y eficaz" frente a las nuevas teorías que circulaban por el mundo y que procuraban transformar "la fisonomía actual del Estado y remover definitivamente los principios substanciales sobre los que se apoya el régimen democrático."11

En 1935, nuevamente la bancada concordancista presentó el proyecto que pautaba la incorporación automática de los miembros y esta vez fue aprobado, ${ }^{12}$ sin la cláu-

6 Matienzo (1931: 45).

7 Cámara de Senadores de la Nación Argentina, Diario de Sesiones (CSDS, en adelante), T. I., 11 de junio de 1932: 679-681.

8 CSDS, T. I, Intervención del senador Ceballos, p. 680.

9 CSDS, T. I, Intervención del senador Arancibia Rodríguez, p. 680.

10 En 1924 las sesiones preparatorias habían insumido 48 días; en 1926, 64 y en 1930 los debates culminaron unos días antes del golpe, cuando el período legislativo estaba a punto de fenecer.

11 Cámara de Diputados de la Nación Argentina, Diario de Sesiones (CDDS, en adelante), T. I, 24 de abril de 1934, p. 8. Intervención del miembro informante de la Comisión de Poderes, el legislador demócrata nacional, Adolfo Vicchi.

12 CDDS, T. IV, septiembre 24 y 251935 : 152 y 400-403. Para Halperin (2004: 165) es, junto con la reforma de la ley 8871 y la intervención a Santa Fe, uno de los cambios que da paso, desde la república del limbo, a la república del fraude. 
sula cuestionada en 1932. Los diputados se incorporaban y ejercían sus funciones mientras la Cámara no declarara la nulidad. Los oradores que intervinieron en la sesión enfatizaron que se estaba dando forma a viejas convicciones, ajenas a los "obscuros propósitos políticos" que se le atribuían. Se eliminaba la exageración y el abuso que la dilatada actuación de la Comisión de Poderes implicaba y que había llegado al colmo en 1930 cuando las sesiones preparatorias finalizaron a un mes del cierre del período parlamentario (que, de todos modos, clausuró el golpe). Se sancionó sin debate. El radicalismo se aprestaba a levantar la abstención.

\section{Fraude y "debate político"}

En 1933, en el mensaje que dio inicio al segundo período legislativo, el presidente Justo no dejó de señalar las diferencias con la etapa precedente en relación al funcionamiento del Congreso y a su relación con el Ejecutivo. Dijo que el acto mismo de pronunciar un discurso frente a las cámaras y el hecho de que éstas podían contar invariablemente con la presencia de los ministros para informarlas y facilitar su tarea implicaban separarse de los cuestionamientos más fuertes que se habían hecho contra Yrigoyen -su ausencia y la de sus ministros en el recinto- y expresó su satisfacción por la ausencia de mayorías regimentadas, dóciles al Poder Ejecutivo y de campañas de obstrucción de una oposición que, por el contrario, cumplía con su función fiscalizadora. ${ }^{13}$

Cuando Justo celebra la "ausencia de mayorías regimentadas" alude a que la coalición gobernante ${ }^{14}$, aunque mayoritaria, tenía serias dificultades para conseguir un voto disciplinado ${ }^{15}$. Sin embargo, aunque sus resultados no fueron siempre los esperados, desde junio de 1932 se organizó lo que dio en llamarse la "concordancia", principio de estructuración de una cierta inteligencia parlamentaria que pudiera derivar en acuerdos políticos más estrechos entre sus miembros. En cuanto al rol de la oposición, los socialistas ${ }^{16}$, que constituían el grueso de la bancada opositora, admitían que necesitaban justificar su lugar, que sabían producto de la abstención radical, y enfatizaron su moderación y serenidad que les permitió participar en la sanción de leyes importantes para el país:

No somos factores de perturbación, no hacemos de la política un simple juego de oposición. No hemos podido ofrecer un testimonio más elocuente y terminante de la lealtad de nuestra conducta, que nuestra actitud durante estos primeros meses de vida parlamentaria, en que hemos acallado la voz de nuestros grandes principios y puesto sordina a nuestras habituales exigencias, dando así pruebas de que comprendemos y sentimos la realidad política de la Nación y sus justificadas exigencias actuales (...). ${ }^{17}$

13 (4 de mayo de 1933). El mensaje, La Nación, Buenos Aires.

14 En 1932, la abstención radical había posibilitado el triunfo de la alianza conformada por demócratas nacionales, socialistas independientes y radicales antipersonalistas que se tradujo en 57, 11 y 16 diputados, respectivamente.

15 Para una reflexión general sobre la disciplina y la relación entre presidentes y congresos, Mustapic (2000).

16 La Alianza Civil constituida por socialistas y demócratas progresistas obtuvo una representación más numerosa de la que les hubiera correspondido (43 y 14 diputados, respectivamente) debido al aporte de votos radicales.

17 Repetto (1957: 26). 
La composición y la dinámica de la cámara no variaron sustancialmente hasta 1936 cuando, aun con el ejercicio del fraude sistemático, se incorporaron 43 diputados radicales. En sus memorias, Federico Pinedo evaluó que hasta ese momento el Congreso contaba con "títulos para figurar entre las mejores asambleas legislativas que ha conocido la República”:

\begin{abstract}
Sé muy bien que la masa de sus componentes, venidos de todos los rincones del país y de todas las clases, no ha mostrado siempre el refinamiento y la firmeza espiritual que caracterizó a los exponentes de algunos congresos patricios. Los modales señoriales de antaño no reaparecieron y hubiera sido difícil que reaparecieran entre hombres de otra extracción. (...) las discusiones subieron algo más de tono en alguna ocasión; pero en cambio en muchas sesiones trabajosas los debates pusieron de manifiesto una información sobre los problemas de la hora, tanto más complicados que los de los tiempos de la oligarquía, que no siempre se encuentra en controversias que han pasado a la historia. ${ }^{18}$
\end{abstract}

La evaluación resultaba tanto de la comparación con los congresos "oligárquicos”, como de los que incluían a los radicales, previos y posteriores. El énfasis de Pinedo, al igual que el de Justo, estaba en el hecho de que en las comisiones y en el recinto se imponía la colaboración, sin que importara sometimiento de la oposición, ni necesaria coincidencia de la bancada oficialista con el gobierno. Fue a partir de la incorporación de los radicales, que todo lo que el gobierno había tenido de "vigoroso y creador", "tocó su fin". "Un Congreso estéril y bullanguero, ocupado preferentemente de cuestiones electorales, en que volvió a hacerse sentir el ausentismo y la obstrucción como suprema arma política, reemplazó al laborioso Congreso iniciado el año 32" (Pinedo, 1946: 181). Uno de los ejemplos de que se valió fue la áspera polémica, las objeciones y los "terroríficos pronósticos" que rodearon el debate sobre las leyes de bancos, para reivindicar el momento y el modo en que se hizo. De no haberse sancionado a principios de 1935, dice, no hubiera tal vez podido hacerse más tarde dada la "casi absoluta esterilidad legislativa" padecida desde 1936. Lo cierto es que entre 1932 y 1935 se plasmaron las principales iniciativas que, por un lado, transformaron el sistema económico y financiero ${ }^{19} \mathrm{y}$, por otro, las reformas que tendieron a redefinir el mapa político para evitar el avance del radicalismo: la modificación del sistema de incorporación de los miembros a la cámara, la ampliación de las causas de inhabilitación de electores ${ }^{20}$ y la eliminación del tercio en la elección de electores para presidente

\title{
18 Pinedo (1946: 127).
}

19 La profundización del control de cambios y la creación de la Junta Reguladora de Granos no pasaron por el Congreso, mientras que la reforma del sistema bancario -creación del Banco Central, del Instituto Movilizador de Inversiones Bancarias, ley de bancos y modificación de los estatutos del Banco de la Nación y del Banco Hipotecario Nacional- fueron producto de una larga diagramación previa y finalmente el parlamento aprobó las seis leyes (12155 a 12160) con la oposición de socialistas y demócratas progresistas. La regulación de la producción, a través de la creación de las Juntas, se inició por decretos que fueron cristalizando en leyes y fue también el parlamento, el que se hizo cargo de introducir modificaciones a lo largo de la década, al igual que en relación a los nuevos impuestos que, creados por el gobierno provisional fueron refrendados por el Congreso en 1932 y modificados a lo largo de la década con la participación de todos los sectores.

20 Las nuevas inhabilitaciones se estipularon en un proyecto presentado por Manuel Fresco, quien argumentó que eliminar a los delincuentes del padrón evitaba el imperio del número y consolidaba el gobierno de los más capaces elegidos por los ciudadanos más dignos (Persello, 2015). 
y vice para que la opinión de la mayoría no pudiera ser defraudada por un conjunto de minorías relativas. ${ }^{21}$

El "congreso estéril y bullanguero" le debió mucho al conflicto derivado del juicio al fraude que trabó por largos períodos la labor parlamentaria. En 1936, junto con las impugnaciones presentadas por la oposición ${ }^{22}$ se debatió ampliamente el sentido de la reforma que posibilitaba la incorporación automática. Los legisladores de la concordancia sostuvieron que una vez constituida la cámara, la incorporación de los diputados era definitiva y que aun estando en juego sus propios diplomas tenían derecho a votar:

(...) .no podemos aceptar la doctrina curiosa y anodina, según la cual el mandato legislativo de los diputados se ejerce en dos períodos: el uno, que es transitorio, durante el cual son diputados en potencia (...) el otro, que es el período en que entran al pleno ejercicio de sus funciones y que de acuerdo con el sistema que se pretende sostener no tendría principio aunque sí tendría fin (...) traería la nefasta consecuencia para el Parlamento de que las elecciones realizadas en un distrito pueden ser impugnadas durante un período indefinido. ${ }^{23}$

La oposición enfatizó que la causa de la reforma era el levantamiento de la abstención de los radicales y, a partir de allí, la necesidad de imponer al sucesor del presidente, que se había iniciado con la reforma de la ley Sáenz Peña y continuado con la intervención a Santa Fe y el oficialismo lo admitió. Se trataba, dijeron, de un problema político. Los "desalojados" el 6 de septiembre, cansados de la abstención e impotentes para la revolución, se incorporaban a la vida política y ostentaban "exacerbados sentimientos de revancha" cuando tenían "la tremenda responsabilidad de dos presidencias que pusieron al país al borde de la ruina"24, no tenían, entonces, autoridad ética, derecho moral para acusar, para constituirse en jueces. "Llevan en su entraña, certificadas por el ejército y la historia, las taras de la inmoralidad, de la concupiscencia y de la demagogia" -sostuvo el diputado Loncan- y eso los inhibía "para erigirse en custodias vestales del pueblo y en tutores de la dignidad nacional." 25 No se justificaban -siguió- los excesos del legalismo, no se podía "rehabilitar de oficio a los prófugos y a los delincuentes del

\footnotetext{
21 CDDS, 25 y 26 de septiembre de 1935, pp. 392-400.
}

22 Se pidió la revisión de los diplomas de Santa Fe, la nulidad de las elecciones de Mendoza y de Buenos Aires y estas últimas se fundaron en una larga lista de cargos: presidentes de comicio inhabilitados para ejercer sus cargos por impedírselo elementos del oficialismo, secundados por la policía o a quienes se obligaba, sin permitírseles retirarse, a entregar sobres firmados para utilizarlos en el procedimiento de la "cadena", y a consentir irregularidades; fiscales impedidos de llegar a las mesas o expulsados y ciudadanos detenidos arbitrariamente o que expresaban no poder votar porque la policía "bloqueaba" los comicios a quienes previamente habían sido identificados como opositores por los "fiscales de calle" y sólo franqueaba el paso a los que exhibían credenciales especiales, especie de contraseña para tener acceso al comicio en las que se leía "Déjelo votar que es de los nuestros". Y, finalmente, se trataba de comicios en los que no existía cuarto oscuro y en los cuales se obligaba a los electores, con intimidación, a votar a la vista; y otros en los que sí existía, pero en los que personas extrañas obligaban a los electores a introducir en los sobres la boleta oficialista y comités opositores clausurados con diversos pretextos. En las provincias eran comunes las denuncias del cambio de urnas en el correo y también se incluía entre las maniobras fraudulentas el desdoblamiento, aunque esta práctica formaba parte de las zonas grises que la ley no reglamentaba. El análisis, interpretación y descripción de los mecanismos del fraude implementado en los comicios bonaerenses a lo largo de toda la década están exhaustivamente tratados en Béjar (2005).

23 Intervención del diputado Pastor. CCDS, 17 de junio 1936, p. 811.

24 CCDS, 17 de junio 1936, p. 827.

25 Intervención del diputado Loncan, CCDS, 17 de junio 1936, p. 818. 
6 de septiembre", había que asumir la responsabilidad de impedir, como lo había hecho el gobernador Fresco en Buenos Aires, que "la horda fugitiva (...) se adueñara, orgullosa y ensoberbecida, del primer baluarte político de la República”. ${ }^{26}$

El conflicto que siguió al debate es conocido. Los legisladores concurrencistas tucumanos y los liberales de Corrientes acompañaron a radicales, socialistas y demócrata progresistas en la moción que impedía el voto de los impugnados. El sector de la concordancia se retiró para imposibilitar el quórum y los reiterados pedidos de que fueran compelidos por la fuerza pública a reintegrarse fueron desoídos por el ministro del Interior, Ramón Castillo. En sus memorias, Nicolás Repetto sostiene que se trató de un "momento sombrío en el proceso de degradación de nuestro sistema de sufragio". Las sesiones estuvieron atravesadas por "interminables chicanas" y "audaces amenazas" y con el pretexto de que los diplomas fraudulentos habían sido impugnados después de prestado el juramento, el oficialismo colocó a la Cámara en la imposibilidad de pronunciarse y de anular la entrada "del más grande contingente de diputados fraudulentos llegándole hasta esta fecha". ${ }^{27}$

A mediados de septiembre se realizaron algunas sesiones para tratar exclusivamente los proyectos que se consideraban más urgentes, tregua parlamentaria, que algunos radicales críticos del accionar de la bancada de su partido consideraron "un éxito de la política oficial y una capitulación de las fuerzas democráticas", que dio paso a una "pacificación" que traspuso "el límite de lo previsto, hasta hacer desaparecer toda diferenciación"

Bajo la apariencia formal de inocuas discusiones parlamentarias todas las iniciativas oficiales han obtenido de parte de los sectores populares de la Cámara el más franco auspicio. (...) oposición parlamentaria totalmente anonadada y desorientada. (...) sus fueros cercenados y sus prestigios maltrechos, a la par que lo ha convertido en un organismo auxiliar del P.E. que éste maneja por hilos invisibles, cuando no por medio de promesas seductoras $(\ldots)^{28}$

De hecho, las impugnaciones quedaron sin resolverse y antes de que se cerrara el período legislativo de 1937 el bloque demócrata manifestó "su decisión de contribuir al regular funcionamiento del Congreso para la sanción de leyes de interés general", pero no "prestar su colaboración para la realización de sesiones dedicadas al planteamiento de cuestiones de carácter exclusivamente político",lo que incluía desplazar las minutas y pedidos de informes. Le atribuían al bloque radical la intención de evitar la constitución de la asamblea legislativa que juzgaría la elección presidencial, en la medida en que persistían en anular diplomas. El diario La Nación le atribuyó al Poder Ejecutivo la paralización de la acción del Congreso y a la "huelga parlamentaria", "intereses banderizos": la derecha había desertado de sus bancas y evitaba la deliberación para impedir la fiscalización.

26 Intervención del diputado Loncan, CCDS, 17 de junio 1936, p. 821.

27 Repetto (1957: 81).

28 (16 de noviembre de 1936). Glosas políticas. La tregua parlamentaria y sus consecuencias Hechos e Ideas, Año 2, vol. IV, núm. 16, p. 297. 
Como resultado, sólo se sancionaron cuatro leyes, de las cuales dos otorgaban licencia al presidente y al vicepresidente de la Nación para ausentarse de la Capital. ${ }^{29}$

En el mismo tono crítico, el matutino analizaba las elecciones presidenciales. No sólo se había instrumentado el fraude en una magnitud sin precedentes, sino que había desaparecido la ficción de la legalidad y había predominado el "sentimiento de jactancia en saltar las vallas legales”30. La bancada radical pasó de 43 a 64 miembros, en detrimento de los socialistas que contaban sólo con 5 representantes. Los diplomas se aprobaron, pero entre el 9 de junio y el 1o de julio se reabrió el debate para considerar la anulación de las elecciones impugnadas, no sólo por la oposición sino por los partidos que formaban parte de la concordancia. ${ }^{31}$

Los legisladores bonaerenses que sostenían al gobernador Fresco defendieron los diplomas impugnados en nombre de la eficacia de la labor legislativa y sostuvieron que para la conservación de las instituciones representativas no importaba que los títulos de algunos de sus miembros fueran deficientes. Juan Káiser argumentó que la anormalidad y la violencia sistemática de los oficialismos era censurable sólo si no tenía la atenuante "de estar al servicio de la civilización o de una causa noble"; pero eran un mal necesario ante la inminencia de un peligro y se justificaban para asegurar la estabilidad de "un gobierno de hombres capaces"32. No era muy diferente a lo que Justo sostuvo en las sesiones de apertura del Congreso en 1937 cuando su mandato llegaba a su fin.

Sin embargo, la defensa del "gobierno de los capaces" se interceptaba con formas diferentes de concebirlo. El legislador Mugica, después de asumir que estaba cómodo dentro de los postulados de la Constitución, se definió como demócrata cristiano, cultor de la Rerum Novarum y de la Quadragesimo Anno y del lema Dios, Patria y Hogar, en los cuales entendía que reposaba la estructura económica, jurídica y social argentina. La eficacia se anteponía a los títulos de los representantes porque la fuerza del pueblo, indiferenciado y amorfo, "debía ser canalizada y conducida por una voluntad inteligente y superior". ${ }^{33}$

Mientras el presidente Ortiz se manifestaba partidario del saneamiento del comicio y obraba en ese sentido, en las sesiones legislativas de 1940, la Cámara de Diputados reformó su reglamento interno y en el capítulo sobre sesiones preparatorias mantuvo la incorporación automática de sus miembros, aunque para evitar los largos debates de 1936 y 1938 reguló el procedimiento: tiempos, clases de impugnaciones, agentes que podían promoverlas y modo en que los reclamos debían sustanciarse. Los legisladores y comités nacionales de los partidos eran los únicos que podían presentar impugnaciones; los despachos de comisión sobre la materia se considerarían en sesiones especiales, fuera de los días señalados para

29 (29 de septiembre de 1937). Un año perdido, La Nación, Buenos Aires, p. 8.

30 (20 de septiembre de 1937). El final del período presidencial, La Nación, Buenos Aires, p. 6.

31 Los antipersonalistas denunciaron fraude en Jujuy, los conservadores sanjuaninos en las elecciones en su provincia y Néstor R. Lencinas, en las de Mendoza.

32 CDDS, 10 de junio de 1938, p. 855.

33 CDDS, 9 y 10 de junio de 1938, p. 758-760. 
las reuniones ordinarias y si no había resolución antes del 31 de julio eran desestimadas y, finalmente, los diputados impugnados podían participar del debate pero no tenían voto.

En tanto, el enfrentamiento siguió dominando la dinámica parlamentaria cuyo ritmo lo imponía una sucesión de pedidos de interpelación iniciados por el bloque demócrata y motivados por las intervenciones federales, el debate sobre la compra de tierras de El Palomar ${ }^{34}$ y, más tarde, sobre la renuncia del presidente, finalmente rechazada. La situación se prolongó en las sesiones extraordinarias. Los radicales declararon nuevamente una "tregua parlamentaria" hasta tanto no se resolviera la cuestión de las elecciones de Santa Fe, a las que luego se sumó Mendoza. El bloque oficialista apeló a las autonomías provinciales; el presidente en ejercicio, Castillo, realizó un pedido de colaboración legislativa para dar cumplimiento a la función de legislar, urgente en las circunstancias por las que atravesaba el país. Se había frustrado la discusión del Plan de Reactivación Económica presentado por el ministro de Hacienda y aprobado por el Senado y la autorización legal para poder hacer uso de los créditos concertados en los Estados Unidos con la finalidad de apoyar la cotización del peso en relación al dólar, para evitar las exportaciones de oro si quería seguir manteniéndose un caudal de importaciones adecuado a las necesidades del mantenimiento de industrias indispensables. El presidente intentó resolverlo por decreto, pero Estados Unidos exigía que fuera el parlamento el que lo refrendara.

Pinedo, para destrabar la situación, inició, en enero de 1941, una serie de encuentros con líderes de los partidos políticos. Comenzó a hablarse de que el ministro buscaba una tregua política y el propio Pinedo se encargó de manifestar que era más que eso, se trataba de un acuerdo amplio que no suponía la desaparición de los partidos, poner al país bajo tutela, ni suspender el funcionamiento de las instituciones o concertar acuerdos de jefes a espaldas de la ciudadanía, sino de una conciliación sin humillaciones, sin venganzas, sin renunciamientos vergonzosos", producto de la reunión de las personalidades representativas. El procedimiento en el que había pensado Pinedo era que un tercio o la mitad de las listas de candidatos para las próximas elecciones fueran confeccionadas de común acuerdo -o por un tercero-, dejando a cada partido el derecho de completarlas con sus propios candidatos. La elección popular tendría en ese caso por resultado consagrar las candidaturas de las personalidades cuyos nombres figuraban al mismo tiempo en las diversas listas, y daba también lugar a los candidatos propios del partido triunfante.

Los radicales, después de conocidos los términos de la entrevista realizada en Mar del Plata entre Pinedo y Alvear, se opusieron en todos los tonos a cualquier entendimiento con los argumentos de que detrás de la tregua estaba Justo, que intentaba volver a posicionarse como presidenciable, que la conciliación era la muerte de los partidos y que el fraude no era una mercancía con la que se pudiera negociar.

34 En un libro reciente, Ignacio López (2018) analiza minuciosa y exhaustivamente estos episodios, la trama de acuerdos y oposiciones en las situaciones provinciales y entre el oficialismo y la oposición en el Congreso. 
Pinedo renunció alegando que seguramente había equivocado el procedimiento o la oportunidad porque las fuerzas políticas, aun aquellas con las que había colaborado, rechazaban su iniciativa. A esa altura, el mantenimiento del fraude era un dilema el que había que salir y el intento de Pinedo fue uno, entre otros, para resolverlo. Mientras Ortiz, en uso de licencia, opinó que la actitud radical era la que correspondía a un partido democrático; Castillo la consideró "subversiva". "Se dice que no se hace lo fundamental porque existe fraude. Dejemos lo de fraude por un momento a un lado. El fraude no se corrige con intransigencias. (...) Habrá que dotar al país de leyes orgánicas, sabias, tales como las de organización de los partidos políticos" ${ }^{35}$

El último intento antes del golpe de junio de 1943 para salir del dilema en que se encontraba el país, fue el anteproyecto de Código Político elaborado por el ministro del Interior, Miguel Culaciati, con el objetivo de "reglamentar la forma representativa de gobierno" y "evitar los escamoteos de la voluntad popular que tanto han dividido la familia argentina y que tantas zozobras han hecho sufrir a la Nación"36. Se ocupaba de las elecciones, la justicia electoral y la reglamentación del funcionamiento de los partidos políticos, cuestión ésta última sobre la que se habían acumulado una importante cantidad de proyectos parlamentarios presentados por todos los sectores.

\section{Hacer la ley}

\section{Políticos, técnicos y representantes de intereses sectoriales}

En 1934, cuando Manuel Fresco asumió la presidencia de la Cámara de Diputados sostuvo que "El ojo avizor de los descreídos de la institución parlamentaria atisba, escudriña, analiza su desenvolvimiento y hace cada día más prosélitos”. Correspondía destruir esa corriente de opinión con un "parlamento técnico, prolongación insensible de las comisiones internas."37

Hacia mediados de la década, el propio parlamento se hizo cargo de la cuestión y comenzó a revisarse el supuesto de que entre 158 representantes del pueblo se contaría siempre con expertos en materias disímiles que obtuvieran información precisa en dependencias idóneas del Estado o informes proporcionados por los propios ministros de lo cual surgiría la acumulación conveniente de datos a fin de que las leyes respondieran a la necesidad y tuvieran una contextura adecuada. Muchos consideraban que era necesaria la creación de consejos técnicos de asesoramiento, ajenos a los compromisos electorales, que podrían empezar a ser expresión de los intereses sociales adecuadamente consultados, para que estudiaran previamente las cuestiones propuestas. ¿Técnicos o expresión de intereses sociales? La cuestión era que ambas expresiones, muchas veces, remitían a

35 (2 de febrero de 1941). Apela a la juventud el Dr. Castillo, La Nación, Buenos Aires, pp. 1-9.

36 (21 de febrero de 1943). Del mensaje que precede al proyecto publicado en La Capital, La Nación, Buenos Aires, p. 1.

37 CDDS, T. I, 27 de abril de 1934, p. 171. 
los mismos sujetos. Ganaderos, industriales, comerciantes, eran expertos en las actividades que los involucraban y su asesoramiento era imprescindible para diagramar las leyes que afectarían al sector.

A esa altura, la asistencia técnica bajo la forma de la información y el consejo ya se habían instalado en el engranaje administrativo a partir de la creación de comisiones y juntas que reunían a funcionarios, técnicos y representantes de intereses sectoriales, como instancia para resolver el problema que la complejidad de la crisis planteaba, aunque no necesariamente supusiera una alternativa a las instituciones de la democracia liberal sino la superación de los que se percibían como déficits.

En relación al parlamento, si bien la posibilidad de instaurar una segunda cámara que representara intereses colectivos no había obtenido consenso en el momento en que se debatió, asociada a la reforma constitucional propuesta por el gobierno de Uriburu, el problema de cómo zanjar los déficits asociados con la representación por partidos, quedó pendiente y los propios legisladores se hicieron cargo de elaborar proyectos que suponían la búsqueda de mecanismos compensatorios; aunque en paralelo siguieron multiplicándose las iniciativas para organizar más racionalmente a los partidos y superar las formas que se consideraban patológicas en relación a la selección de candidatos.

A principios de 1936, La Nación publicó una larga entrevista a Julio Oscar Ojea, abogado del foro de Mercedes (Buenos Aires) y miembro del Instituto Argentino de Estudios Legislativos, una sección de especialización de la Federación Argentina del Colegio de Abogados creada a fines de $1935 .{ }^{38} \mathrm{El}$ motivo era analizar un pedido de la Unión Industrial Argentina al Poder Ejecutivo para que convocara a sesiones extraordinarias con el objetivo de suspender la aplicación de una ley por problemas de interpretación ${ }^{39}$. Ojea sostuvo que un texto legal era más perfecto cuando evitaba entrar en el terreno de las interpretaciones. Y de allí derivó una reflexión en torno a las capacidades que requería la tarea de legislar. ¿Bastaba que los comicios ungieran a un ciudadano diputado o senador para suponerla o era indispensable recurrir a la colaboración técnica?

El Instituto de Estudios Legislativos había surgido de una modificación de la estructura y funcionamiento de la Comisión Permanente de Estudios Legislativos, instituida por la segunda Conferencia Nacional de Abogados reunida en Córdoba en 1926 y su objetivo era "propender al estudio y redacción de las leyes, y asesorar como cuerpo técnico a los poderes públicos en cuestiones jurídicas de interés

38 (13 de enero de 1936). Es necesario variar el sistema que rige para dar forma a las leyes. La Nación, Buenos Aires, p. 6.

39 Se trataba de la 11729, que había establecido modificaciones al Código de Comercio para reglamentar, entre otras cuestiones, indemnizaciones y vacaciones. El conflicto se había originado en la interpretación de la ley. Cuando fue sancionada los miembros informantes del proyecto en el Congreso excluyeron de sus alcances a los obreros industriales, sin embargo, la justicia llamada a expedirse, entendió que estando los talleres y fábricas regidos por el Código de Comercio, la reforma en cuestión los alcanzaba. La Unión Industrial Argentina se opuso persistentemente a su aplicación porque la consideraba parcial q: las cargas económicas que representan para el empleador eran confiscatorias y las obligaciones que éste debía soportar no tenían paralelismo con las del empleado u obrero. 
general". Contaba con comisiones que cubrían prácticamente todo lo legislable: de Derecho Civil, Economía, Finanzas y Estadística, Derecho Administrativo y Legislación laboral y cada una de ellas estaba integrada por prestigiosos juristas y economistas que, a su vez, ocupaban o habían ocupado posiciones en la administración pública o en el Congreso ${ }^{40}$. Tenía relatores especializados, secciones permanentes y accidentales en las sedes de los colegios de abogados del país y corresponsales en el extranjero para obtener información sobre las novedades en doctrina y legislación. Y desde su creación sus miembros se dedicaron a estudiar y proponer enmiendas a los proyectos de reforma del Código Civil, las leyes que fueron configurando el nuevo sistema tributario -combinadamente en las comisiones de economía y derecho administrativo-, el Código de Trabajo y la ley de asociaciones profesionales; los proyectos sobre registro nacional de bienes de los funcionarios públicos y las bases para la organización de las instituciones autárquicas.

El organismo buscaba la forma de "depurar y disciplinar el proceso de elaboración de la ley, librándola de la improvisación, que subvierte su finalidad y esencia”. Ojea recuperaba a León Duguit -la ley "es el acto por el cual el Estado formula una regla de derecho objetivo, o establece reglas u organiza instituciones destinadas a asegurar el cumplimiento de una regla de derecho objetivo"-, para concluir que era necesario determinar normas reguladoras de la función de legislar para todas las etapas que el proceso implicaba: análisis de sus disposiciones, doctrina y legislación comparada, adaptación al medio, coordinación, sencillez y claridad de los preceptos para llegar al fin que se perseguía. De lo contrario las fallas podían ocasionar graves perturbaciones al grupo social sobre el que la sanción recaía.

En la mayoría de los países del mundo, sostenía, los inconvenientes se salvaban con la organización de oficinas técnicas que, de hecho, en el momento de su constitución fueron resistidas por las cámaras y sus comisiones internas. ${ }^{41}$ En el caso argentino funcionaba una Oficina de Información Parlamentaria, inspirada en Estados Unidos y Gran Bretaña, que actuaba como relatora de antecedentes para la ley, dirigida por J. Ladman que, para el jurista entrevistado por La Nación, no era suficiente. El carácter que se le daba al Instituto de Estudios Legislativos, en cambio, era el de gabinete elaborador de la ley. Presentaba sus dictámenes o conclusiones en asambleas en las que se reunían sus miembros con representantes del gobierno y ex magistrados. Esto, en general, no implicaba afirmar que la tarea debía pasar a manos exclusivamente técnicas sino que debía armonizarse experiencia y teoría, mandato representativo y conocimiento especializado.

40 Héctor Lafaille presidía la sección Derecho Civil, Alejandro Ruzo, Economía y Finanzas en la que participaban Guillermo Garbarini Islas, Alfredo Schaffroth, Mario de Tezanos Pinto; Leónidas Anastasi y Dardo Rietti estaban en Legislación del Trabajo; Rafael Bielsa, Eduardo Crespo y Horacio Correa Luna, en Derecho Administrativo.

41 Se refiere a la Societé de Legislation Etrangére y la Societé d’Estudes Legislatives en Francia; en Alemania, la Deutacher Juristentag; en los Estados Unidos el Bureau of Comparative Legislation y The Legislative Counsel; en Gran Bretaña, el Parliamentary Council's Office; en Bélgica, el Institut de Droit Comparé, y en Italia, el Instituto de Studi Legislativi. 
Ese mismo año, Francisco Eyto, legislador radical, presentó un proyecto de resolución para demandar la creación de una Oficina Técnico-Consultiva y de Información Parlamentaria y la bancada demócrata nacional otro que proponía la organización de un cuerpo de consejeros técnicos. ${ }^{42}$ En el primer caso se trataba de una comisión de doce peritos elegidos por concurso. En el segundo, de asesores de las comisiones internas nombrados por cada una de ellas y también designados por concurso. Establecía, además, que éstas debían, en el momento de abocarse al estudio de un asunto, consultar a los organismos públicos o privados especializados (oficinas técnicas, ministerios, tribunales, reparticiones autónomas, facultades, institutos, academias, asociaciones profesionales creadas con fines de interés general) y hacía recaer en el cuerpo diplomático la actualización de la legislación comparada. La Cámara consideró ambos proyectos, unificándolos.

Eyto hizo hincapié en las dificultades de la Oficina de Información Parlamentaria para cumplir con su cometido por carecer de la organización adecuada y del personal necesario. El cuerpo de peritos que proponía las evitaría. Rodolfo Corominas Segura, demócrata mendocino, fundamentó la iniciativa de su sector. Recurrió a la tradición del Consejo de Estado de Napoleón y organismos creados con ese fin en Europa y Estados Unidos y citó Anarquía o jerarquía, el libro donde Salvador de Madariaga sostenía que "la democracia moderna, por la nueva fuerza de las cosas, va transfiriendo a especialistas obscuros y políticamente irresponsables la soberanía que se supone residir en el pueblo". No era eso lo que el proyecto pretendía, dijo. El asesoramiento técnico propuesto debía tener el valor de un consejo. El criterio del legislador debía predominar. Y se refirió también al libro de Joseph Barthélemy, El trabajo parlamentario y el régimen de las comisiones, que prevenía sobre el rol paradojal y a veces excesivo de los cuerpos técnicos que se transformaban en mesas directivas oficiales de las comisiones consagrando la confusión de poderes y apelaba a que los parlamentarios realizaran el esfuerzo de conocer el problema sobre el que dictaminaban. E incorporaba otra de las cuestiones que formaban parte del debate en torno a la representación, la participación de los intereses comerciales, industriales, científicos, artísticos para concluir que no era optimista respecto de lo que podía obtenerse por el fraccionamiento para llegar a una imagen de conjunto y homogénea, más bien podía esperarse que esos intereses chocaran violentamente. El relato que Barthou hacía en El Político del parlamento francés de 1919 integrado por técnicos, especialistas y hombres que representaban todos los intereses sociales, mostraba la decepción de un sistema semejante. Sin embargo, concluía que el deber de la hora era hacer "todas las experiencias necesarias", sobre todo si ellas no comportaban "perjuicios ni riesgos". ${ }^{4}$

Las objeciones más fuertes a los proyectos en debate las plantearon los socialistas y dentro del radicalismo, José Tamborini. Repetto reivindicó la necesidad de asesoramiento técnico en la medida en que no fuera en detrimento del político y cuestionó la creación de oficinas que "degeneran pronto en hongos burocráticos de crecimiento interminable". Tamborini sostuvo que la excesiva insistencia

42 CDDS, 26 de noviembre de 1936, p. 732-734 y 739-755.

43 CDDS, 26 de noviembre de 1936, p. 750. 
en el asesoramiento técnico, llegaba al extremo de "suscitar el equívoco de que se pretendiera una substitución vergonzante o subrepticia del diputado por el técnico, para dar pábulo a ideas corporativistas, tan vastamente discutidas en el momento actual y que, desde luego, no comparto en modo alguno". El trabajo parlamentario, continuó, es susceptible de reformas que lo hagan más eficaz y que desbaraten las críticas de que es objeto, pero sin perder de vista que estas últimas son ataques "solapados" al sufragio universal y a la democracia. Barthélemy y Barthou, concluyó, convinieron en "el desencanto y en el fracaso del Parlamento soi disant técnico" de la posguerra en Francia y el libro de Madariaga "huele a fascismo". Eyto, tratando de distanciarse, sostuvo que la comisión que proponía, aunque inspirada en la cámara italiana, no tenía el mismo "sentido corporativista".

Ninguna de estas iniciativas se sancionó. Persistía el temor frente a las derivas que podría ocasionar la incorporación de la técnica y los intereses y, finalmente, la respuesta vino por el lado de la reforma del reglamento para organizar, jerarquizar y disciplinar el trabajo en el recinto y en las comisiones.

\title{
La reforma del reglamento
}

En 1938, la bancada socialista, ${ }^{44}$ que se había opuesto a la creación de una oficina técnico-consultiva, presentó un proyecto que modificaba el reglamento de la cámara para asegurar una buena y rápida información, sin caer en la "tecnocracia legislativa" y la hipertrofia burocrática. ${ }^{45}$ La cámara era en definitiva "la expresión de la capacidad, organización y disciplina de los partidos" en cuyo nombre actuaban los legisladores. Si se mejoraba la acción política y los partidos "de principios" funcionaban como escuelas de militantes, quienes se incorporaran a los cuerpos colegiados podrían aprovechar la información técnica sin olvidarse de su carácter de políticos:

\begin{abstract}
Respetamos mucho a los técnicos, pero no creemos que de ellos dependa la eliminación de deficiencias que se observan en el trabajo legislativo. No olvidemos que un informe técnico no es indiscutible: a una opinión técnica suele oponerse otra no menos autorizada y lógica. ${ }^{46}$
\end{abstract}

En 1940, sobre la base del proyecto socialista y con la incorporación de aportes de prácticamente todos los sectores reunidos en comisión, la cámara estudió y sancionó una reforma al reglamento interno, ${ }^{47}$ a la que ya nos referimos en lo que a la incorporación de los diputados se refiere. El radical Araujo, miembro de la comisión, informó el despacho. Comenzó afirmando que ni el Congreso ni el Ejecutivo podían sustraerse a la complejidad que implicaba la ampliación de las

44 CDDS, T. II, r. 8, 30 de junio 30 y 1 de julio de 1938, pp. 454-460.

45 La Cámara de Diputados contaba en ese con un personal administrativo y técnico de 153 empleados y el Senado con 77 a los que se sumaban 21 empleados de la Biblioteca, 15 en la Contaduría del Congreso y el personal de maestranza y servicio. Excepto el cuerpo de taquígrafos, no todos los demás accedían por concurso. La preocupación socialista, consistente con sus opiniones en torno a las dimensiones del aparato estatal y el funcionamiento de la administración pública, era que una oficina técnico-consultiva aumentara el personal ya existente.

46 CDDS, T. II, r. 8, 30 de junio 30 y 1 de julio de 1938, p. 455.

47 CDDS, 31 de julio de de 1940, pp. 658-715. 
funciones del Estado y paralelamente se hizo cargo de las críticas de la opinión y de la prensa sobre la inercia, las postergaciones, la frondosidad y el abuso que suponían la reiteración de argumentos, la esterilidad legislativa y el predominio del "debate político". Sin embargo, rechazó la idea de que la institución parlamentaria estuviera en crisis. La propuesta de constituir parlamentos sociales y económicos paralelos al parlamento político, por un lado y el Reichstag alemán, la cámara corporativa italiana o el Congreso panruso, por otro,-dijo-daban cuenta de ello. ${ }^{48}$

La reforma del reglamento se pensaba como un modo de hacerse cargo de la complejidad y superar los vicios de funcionamiento. La "oratoria de campanillas" y el despliegue de conocimientos e informaciones superficiales se consideraban anacrónicas e ineficaces. La magnitud de los problemas a estudiar y resolver no admitían dilaciones y si bien se reconocía que no podía reducirse al parlamento al "límite casi mecánico de fabricar leyes", esa era la tarea prioritaria. Podía ser tribuna pero no "tablado". ${ }^{9}$ Había que establecer formas de abreviar los debates, evitar "la incontinencia verbal", la prolongación artificial de controversias cuya resolución se conocía de antemano. Se fijó, entonces, el término para el uso de la palabra que graduaba a los oradores según fueran presidentes de comisión, informantes, representantes de bloque o simples miembros del parlamento y se reglamentó el tiempo dedicado a las interpelaciones..$^{50}$ La Cámara les dedicaría una hora de cada sesión, pasada la cual la tarea era legislar. El diputado interpelante perdía la posibilidad de usar la palabra sin restricciones y una vez que ésta se aprobara sólo contaba con dos horas y los demás legisladores con media. Los argumentos que justificaban la limitación no eran nuevos. En los años de los gobiernos radicales, el oficialismo había denunciado el exceso de interpelaciones con fines "meramente políticos", para desestabilizar y procesar al Poder Ejecutivo y la oposición, había criticado la ausencia de los ministros para contestarlas. Invertida la ecuación, ahora era el oficialismo el que sostenía que los partidos, a través de la práctica de interpelar, trasladaban sus banderías al recinto y provocaban debates "agrios, ilimitados, borrascosos, obscuros", que sólo agudizaban problemas para después diluirlos, "forma espectacular de eludir las soluciones", porque a diferencia de lo que ocurría en los países de régimen parlamentario, no podían variar las orientaciones del Poder Ejecutivo, corregir desviaciones en la ejecución de las leyes, exigir responsabilidades o derrocar ministerios. ${ }^{51}$

A las cláusulas de disciplinamiento que encorsetaban el debate, se sumaron los capítulos referidos a las comisiones. El diagnóstico que presidía la propuesta era que las éstas vegetaban, que eran apenas "antesalas" o "pasillos de tránsito" y sus miembros firmaban muchas veces los despachos, al final del período de sesiones, en el recinto. El proyecto contemplaba su funcionamiento durante el receso para

48 CDDS, 31 de julio de de 1940, p. 680.

49 CDDS, 5 de junio de 1940, p. 294.

50 Durante del gobierno de Justo se presentaron 35 pedidos de informe y sólo dos fueron rechazados; la gestión de Ortiz respondió a las 8 interpelaciones presentadas y durante el breve período en que Castillo fue presidente, sus ministros fueron convocados en 25 oportunidades y siete no ocurrieron. 
asegurar la continuidad de la labor, al modo del comité permanente de algunos parlamentos europeos y establecía que en el período ordinario sólo se podía dictaminar hasta el 20 de septiembre para evitar las sanciones apresuradas. Para sistematizar el trabajo interno se establecía la obligatoriedad del informe escrito, la limitación del plazo para dictaminar, la oportunidad para los legisladores de introducir enmiendas a los asuntos en estudio o despachados para evitar las improvisaciones en el recinto y la publicidad del trabajo realizado a través de la obligatoriedad de levantar un acta y entregarla a los diarios 24 horas después de realizada la reunión. ${ }^{52} \mathrm{El}$ sistema combinaba la publicidad que caracterizaba el trabajo de las comisiones en el parlamento francés, con la facilidad para convertir en sanciones los despachos no observados, propio de las cámaras inglesas que declaraban ley todo proyecto que dentro de los diez días de depositado en la mesa no hubiera merecido observación de los miembros que las integraban.

Las comisiones pasaron de 16 a 21, con 7 miembros cada una, con excepción de la de Presupuesto y Hacienda que seguía contando con 19 y se reglamentó lo que la costumbre ya había impuesto: la representación proporcional de los sectores en la composición de las comisiones y el derecho de los diputados que no las integraban a participar, sin voto. Se sumaron Juicio Político; Higiene y Asistencia Social; Seguro y Previsión Social, Codificación y Población, inmigración y colonización. Guerra y Marina cambió su denominación por Defensa y Justicia se amplió a Organización, régimen judicial y carcelario. Paralelamente, se fijaron las incumbencias de cada una de ellas. ${ }^{53}$

En general, hubo consenso. Sin embargo, las funciones y el desempeño de la Comisión de Presupuesto y Hacienda provocaron un amplio debate. El proyecto de reforma establecía que no podía incorporar a su despacho sobre presupuesto general de gastos de la administración, ni a su articulado general, ninguna creación de servicios nuevos o disposiciones relacionadas con materias de la competencia de otras comisiones, si el proyecto o solicitud no había seguido el trámite ordinario y no contaba con despacho favorable de la comisión correspondiente. El argumento se basaba en la necesidad de individualizar el origen de toda inclusión en la ley de presupuesto; dar personería a las demás comisiones permanentes encargadas de dictaminar sobre asuntos, que si bien importaban gastos eran de su competencia esencial, y resguardar a la propia comisión de injerencias extrañas que afectaran el plan de gastos y recursos ya trazado.

Hacía tiempo que los legisladores venían dando cuenta de incorporaciones de lo más variadas y confusas a la ley general de gastos y recursos. El presupuesto para 1937 incluía todo género de asuntos: resoluciones sobre impuestos, sobre funciones administrativas, sobre tasas de servicios; había un artículo que declaraba monumento nacional el edificio del antiguo Cabildo de Salta y autorizaba

52 No hemos encontrado registros en la prensa que nos permitan afirmar que la norma se puso en práctica.

53 Catorce comisiones permanentes: Negocios Constitucionales, Presupuesto y Hacienda, Negocios Extranjeros y Culto, Justicia, Obras Públicas, Comunicaciones y Transportes, Industrias y Comercio, Peticiones y Poderes, Legislación General, Legislación Agraria, Legislación del Trabajo, Instrucción Pública, Guerra y Marina, Territorios Nacionales y dos comisiones especiales: Legislación Municipal y Jubilaciones. 
su expropiación; otro que facultaba la revisión del convenio sobre la deuda de Entre Ríos, y un tercero que reproducía las disposiciones de la ley de contabilidad referentes a la preparación del propio presupuesto. En 1938 y 1939 se repitió el mecanismo: modificaciones a los Códigos de Minería y rural; autorización al Poder Ejecutivo para organizar la marina mercante; derogación de la ley de avenidas y el sistema de expropiación vigente en la Municipalidad de Buenos Aires y la creación de la Universidad de Cuyo, todo se incluyó en la ley general de gastos y recursos. $^{54}$

Américo Ghioldi, en nombre de la bancada socialista, desarrolló un ejemplo para "atestiguar el desorden" relativo al anexo de trabajos públicos. Un diputado entrerriano solicitó fondos para construir un balneario en su provincia y otro representante de la misma provincia se opuso. Después de una larga discusión se votaron partidas para "cinco o seis balnearios para otras tantas ciudades entrerrianas". Por otra parte, la cámara votaba recursos para determinadas obras que se ejecutaban según el deseo y la voluntad del Poder Ejecutivo, se incluían obras carentes de estudio técnico; los créditos se transferían año a año, y las obras quedaban inconclusas.

Según la opinión mayoritaria se debía "poner coto de una vez por todas a esa especie de avalancha de última hora con que cada uno de los diputados de todas las provincias piensan cumplir con sus respectivos electores pidiendo la creación de escuelas, de bibliotecas, y de un sinnúmero de instituciones". ${ }^{55} \mathrm{Y}$, además acabar con las inclusiones solicitadas por los ministros para salvar necesidades inmediatas del poder administrador. La Comisión no podía estar sometida a la puja de pedidos o a la gravitación de influencias, por más confesables y lícitos que estos fueran. Sin embargo, hubo quienes sostuvieron que se trataba de legítimas iniciativas que respondían a intereses también legítimos. Por la vía de la Comisión de Presupuesto se resolvían innumerables problemas, grandes y pequeños, que afectaban diferentes aspectos de la vida del país. Si se le quitaba elasticidad y se la convertía en "una máquina registradora de una casa de comercio" se atentaba contra la posibilidad de resolverlos rápida y fácilmente. ${ }^{56} \mathrm{Y}$ advertían que quienes apoyaban las limitaciones serían los primeros en arrepentirse de haberlas propuesto.

Las incumbencias de la Comisión de Relaciones Exteriores y Culto también fueron objeto de debate. El enunciado propuesto, redactado por los socialistas, molestaba a los católicos. En principio, el uso de los plurales "cultos" y "patronatos" en la redacción de la cláusula respectiva, cuando de hecho, según éstos últimos, no había más que un patronato ejercido por el gobierno y los cultos que no fueran el católico, eran personas jurídicas de las que se ocupaba el Código Civil.

54 CDDS, T. II, 1 de agosto de 1940, p. 746-785. 
Por otra parte, el radical Witcomb propuso una enmienda para separar beneficencia, asociada directamente a la iglesia, de asistencia social, con lo cual parte de las atribuciones de la comisión debían trasladarse a la de Asistencia y Previsión social, que creaba el nuevo reglamento y otras, a Trabajo. El argumento era que el Estado debía dejar de hacer beneficencia en el sentido "caritativo"; la sociedad reclamaba funciones y servicios y no favores que, siendo oficiales, se convertían en “concesiones vergonzantes". Y si bien no podían desterrarse todavía por completo esas prácticas, era necesario disociar en el reglamento de la cámara la relación entre beneficencia y acción del estado. ${ }^{57}$

Finalmente, el socialista Juan A. Solari agregó que había que eliminar de la comisión lo referido a los indios y su conversión al catolicismo, en la medida que pertenecía al pasado, y correspondía trasladar la cuestión a la Comisión de Legislación del Trabajo. "Los pocos indios que quedan (...) necesitan ser redimidos en su condición y en su existencia más que socorridos y auxiliados con la bendición del Santo Sacramento y los no menos Santos Evangelios. ${ }^{58}$

En el transcurso del debate, al primitivo proyecto se incorporaron una serie de agregados, entre ellos, los referidos a la Oficina de Información Parlamentaria cuya labor, el Instituto de Estudios Legislativos presidido por Ojea, consideraba insuficiente: los empleados nuevos que se incorporaran debían pasar por un concurso y conocer dos idiomas extranjeros y entre sus funciones se destacó la de poner a disposición de los legisladores material clasificado por comisión (debates, proyectos, antecedentes de legislación nacional, provincial, municipal y comparada). ${ }^{59}$ Se evitaba así la creación de nuevos cuerpos de asesores y se aprovechaba el concurso de lo existente.

La opción por la reforma del reglamento supuso entonces apostar por los políticos en detrimento de la asesoría técnica externa e imputar la dilación y la inactividad a la ausencia de disciplina y de coordinación en la tarea. Si se sujetaba el trabajo parlamentario a principios de orden se evitarían las postergaciones, la inercia, el debate político. Aunque el hecho de que no se organizaran oficinas técnico-consultivas con la participación de personas ajenas al parlamento no supuso que no se convocara a expertos. Una de las formas adoptadas fue la encuesta, aplicada por ejemplo cuando una comisión especial del parlamento se abocó al estudio de los presupuestos de las reparticiones autárquicas con el objetivo de preparar un proyecto de ley que regulara y unificara su funcionamiento. ${ }^{60} \mathrm{En}$

57 CDDS, T. II, 31 de julio de 1940, p. 678.

58 CDDS, T. II, 1 de agosto de 1940, p. 784.

59 CDDS, T. I, 5 de junio de 1940, p. 292.

60 CDDS, 13 de enero de 1937, pp. 328-419. Los llamados a pronunciarse fueron los contadores A. Schaffroth, Juan Bayetto, Alfredo Labougle y Dívico A. Furnkorn. Schaffroth, era miembro del Instituto Argentino de Estudios Legislativos. Bayetto, tenía una larga trayectoria en la administración y en la universidad, se había desempeñado como subsecretario de Hacienda de la Nación durante el gobierno de Uriburu, había sido presidente de la comisión de estudio del régimen administrativo de los Ferrocarriles del Estado, delegado de la Universidad en la administración del Museo Social Argentino, era profesor titular de Contabilidad Pública en la Facultad de Ciencias Económicas y decano de la misma desde 1936, miembro de la Academia Nacional de Ciencias Económicas y asesor técnico de la comisión especial del Senado para la reforma de la ley de contabilidad. Dívico A. Furnkorn era profesor adjunto y Alberto 
otros casos, el Ejecutivo recurrió a la formación de comisiones de expertos para diagramar proyectos que luego se presentaban al parlamento. En abril de 1936 una resolución del Ministro de Agricultura, Miguel Ángel Cárcano, encomendó a una comisión de técnicos el estudio y redacción de un anteproyecto de ley de protección al creador de nuevas variedades de plantas. Y en 1937, con el fin de proyectar una ley nacional de fomento de la investigación agraria, tendiente a organizar en forma permanente el sostenimiento de las estaciones experimentales y laboratorios, dotando a cada zona con los establecimientos técnicos que las necesidades de la agricultura reclamaban, nombró una comisión de ingenieros agrónomos presidida por F. Pedro Marotta. ${ }^{61}$ Los mismos mecanismos se utilizaron para recabar la opinión de los gremios, que no sólo estaban presentes en los debates a través de solicitadas, memoriales y documentos, sino que participaban a través de comisiones consultivas ad hoc, de las cuales las más conocidas, pero no las únicas, son las que diagramaron las leyes que organizaron las juntas reguladoras de la producción.

El último intento, antes del golpe, fue instaurar un Consejo Económico Nacional, donde estuvieran representados todos los intereses, para trabajar conjuntamente con el parlamento, sin reemplazarlo, en la diagramación de políticas, proyecto que había sido ya presentado en la cámara, pero que en la coyuntura era promovido por las corporaciones.

\section{Reflexión final}

La experiencia asociada a los gobiernos radicales y los ecos de derivas y debates externos condujeron, aun a muchos de quienes habían apoyado inicialmente la ampliación del sufragio universal, a cuestionar a la democracia liberal y, por ende, la representatividad y eficacia del parlamento. La crisis ahondó el problema y los golpistas de septiembre se debatieron en la incertidumbre sobre el rumbo a seguir. Las propuestas, inciertas y poco sistematizadas, suponían instaurar la representación corporativa o funcional o establecer un sistema de doble representación. Los partidos se abroquelaron en la defensa de la profundización de los mecanismos democráticos para evitar, en adelante, el ejecutivismo, el personalismo y la demagogia y el propio Uriburu asumió que, de reformarse la Constitución, era el Congreso, órgano que reflejaba la voluntad del pueblo, el que debería resolver su contenido. Lo cierto es que la constitución no fue reformada, ni en un sentido ni en otro, y se fueron instrumentando algunos cambios ad hoc para enfrentar la coyuntura.

Labougle, profesor titular de finanzas, presidente de la Academia de Ciencias Económicas entre 1928 y 1929 y en ese momento presidente de la Contaduría General de la Nación.

61 F. Pedro Marotta fue presidente entre 1932 y 1937 de la Academia Nacional de Agronomía y Veterinaria, del Centro de Ingenieros Agrónomos y decano de la facultad respectiva entre 1927 y 1931 y 1936 y 1940 y con una larga carrera en la administración. 
Esos cambios involucraron al Congreso que, por un lado, sin la presencia de los radicales en la primera mitad de la década, se dispuso a acompañar al Ejecutivo y evitar, hacia adelante, la posibilidad del regreso del partido depuesto. El uso del mecanismo del fraude, transgresión a los principios del gobierno representativo, se implementó en nombre de la "buena administración". "Estábamos haciendo una gran obra -dirá Pinedo- y "había que salvarla de la incompetencia de los posibles rivales" (1957: 165-166), que no eran otros que los radicales, a los que los diputados concordancistas les negaban "autoridad moral" para constituirse en defensores de la legalidad. En el mismo sentido el presidente Justo anteponía la forma en que se desempeñaban los legisladores y la acción que desarrollaban a favor del pueblo a la pureza de sus títulos. Y quienes justificaban el fraude en voz alta lo hacían porque lo consideraban un mal necesario en pos de instaurar un "gobierno de hombres capaces". La aceptación de la irreversibilidad del sufragio como principio de legitimación del poder se interceptaba con la "necesidad" de corregir sus resultados. El parlamento estableció la incorporación automática de sus miembros, sancionó una ley que aumentaba las inhabilitaciones para integrar el padrón electoral y otra que suprimía la representación de la minoría para la elección de electores. Buscó en la ley mecanismos que le permitieran traducir esa "corrección" que, en definitiva, acompañaron el fraude, recrudecieron el "debate político" cuando, finalmente, los radicales ocuparon bancas en el Congreso, y no resolvieron el dilema al que la clase política se enfrentaba. La intención de sanear el sistema manifestada por Ortiz, los acuerdos políticos que imaginó Pinedo en 1940 para la confección de listas de candidatos, el Código Político que proyectó el ministro del interior Miguel Culaciati antes del golpe, dan cuenta de ello.

Por otro lado, el rechazo de una reforma constitucional que instaurara alguna forma de corporativismo, si bien contundente, no cerró el debate sobre la relación entre la política, los intereses y la técnica. ¿Bastaba, tal como planteaba Ojea en 1936, que los comicios ungieran a un ciudadano diputado o senador para suponerle capacidad para legislar o era indispensable recurrir a la colaboración técnica? ¿No era necesario combinar mandato representativo con conocimiento especializado? Y, finalmente, ¿el conocimiento especializado, no residía también en aquellos involucrados directamente en las actividades sobre las que se pretendía legislar? La pregunta acerca de cuán representativo y eficaz podía ser un parlamento que en la diagramación de las leyes se valía sólo del saber y la experiencia de legisladores surgidos de listas confeccionadas por los partidos políticos y seleccionados a partir del sufragio, atravesó la posguerra y fue independiente del fraude. La tarea de legislar requería "hombres capaces" y eso justificaba la exclusión de los radicales, pero no era suficiente para afrontar la complejidad.El parlamento se dio ese debate a través de propuestas para crear en su seno comisiones que incorporaran la voz de los técnicos y en él se filtró el temor frente a la posibilidad de que éstos reemplazaran a los políticos y de que se implantara, de manera encubierta, alguna forma de corporativismo. La respuesta vino por el lado de la reforma interna del reglamento para ordenar el uso de los tiempos, racionalizar el trabajo de las comisiones y fortalecer la oficina técnica de la propia cámara con el objetivo de lograr mayor racionalidad, eficacia y eficiencia. Todos los sectores de la cámara coincidían en que el político debía prevalecer. Sin embargo, 
a pesar de que no se institucionalizaron, se multiplicaron las instancias de consulta con expertos y miembros de las corporaciones a las que se involucró en la diagramación de las leyes que crearon los organismos surgidos como producto de las nuevas funciones que el Estado asumió y poco antes del golpe de 1943, el debate volvió a instalarse a partir de la demanda de las corporaciones de crear un Consejo Económico Nacional. 


\section{Bibliografía}

" Béjar, M. D. (2005). El régimen fraudulento. La política en la provincia de Buenos Aires,

"1930-1943, Buenos Aires, Siglo XXI.

"Cantón, D. (1966). El parlamento argentino en épocas de cambio: 1890, 1916 y 1946, Buenos Aires, Editorial del Instituto.

" Cattaruzza, A. (dir.) (2001) Crisis económica, avance del estado e incertidumbre política (1930-1943), Nueva Historia Argentina, Tomo VII, Buenos Aires, Sudamericana.

"Devoto, F. (2005). Nacionalismo, fascismo y tradicionalismo en la Argentina moderna. Una historia, Buenos Aires, Siglo XXI.

" De Privitellio, L. (2011). Las elecciones entre dos reformas: 1900-1955, Sábato, H. et al, Historia de las elecciones en la Argentina, 1805-2011. Buenos Aires: El Ateneo.

" Cámara de Diputados de la Nación (1951). El parlamento argentino 1854-1951. Buenos Aires: Imprenta del Congreso de la Nación.

" Ferrari, M. (2008). Los políticos en la república radical. Prácticas políticas y construcción de poder. Buenos Aires: Siglo XXI.

" García Garino, G. (2017). Una mirada al funcionamiento de una legislatura provincial: reglamento, asistencia y disciplina interna, 1852-1880. Ponencia presentada en las XVI Jornadas Interescuelas de Historia, Mar del Plata.

" Halperin Donghi, T. (2004). La república imposible (1930-1945). Buenos Aires: Ariel.

" Halperin Donghi, Tulio (2003) Argentina y la tormenta del mundo. Ideas e ideologías entre 1930 y 1945 . Buenos Aires: Siglo XXI.

" Lanteri, A. L. y Nanni, F. (2016). Espacios legislativos y políticos en la Argentina del siglo XIX. Las legislaturas. Dossier núm. 88, Programa Buenos Aires de Historia Política, dossiers/ historiapolitica.com.

" López, I. (2018). La república del fraude y su crisis. Política y poder en tiempos de Roberto M. Ortiz y Ramón S. Castillo: Argentina, 1938-1943. Rosario: Prohistoria.

" MacKinnon, M. (2017). El congreso en Chile y Argentina a la hora de la legislación laboral. Ponencia presentada en las XVI Jornadas Interescuelas de Historia, Mar del Plata.

" Matienzo, J. N. (1931). Remedios contra el gobierno personal. Buenos Aires: Librería Anaconda.

" Molinelli, N. G. (1991). Presidentes y congresos en Argentina : mitos y realidades. Buenos Aires: Grupo Editor Latinoamericano.

" Mustapic, A. M. (2000). Oficialistas y diputados: las relaciones ejecutivo-legislativo en la Argentina, Desarrollo económico, vol. 39, núm. 156, pp. 571-595.

" Ortiz de Rozas, V. (2017). Aproximaciones al estudio del Congreso Nacional Argentino. Contrastes, convergencias y agentes de investigación, Estudios Sociales 52 (1), pp. 65-92.

"Persello, A. V. (2004). El partido radical. Gobierno y oposición, 1916-1943. Buenos Aires: Siglo XXI.

"Persello, A. V. (2015a). La ingeniería institucional en cuestión en la Argentina de los años '30. Del "estado consultivo" al "gobierno de los funcionarios. En De Privitellio, L. y López, I. La década del 30, Dossier nro. 53, historiapolítica.com. 
"Persello, A. V. (2015b). No quiero para mi país el voto de los delincuentes, Revista Pasado Abierto, CEHIS, año I, núm. 2, pp. 38-57.

" Pinedo, F. (1946). En tiempos de la República, T. I., Buenos Aires: Ed. Mundo Forense.

" Repetto, N. (1957). Mi paso por la política (De Uriburu a Perón). Buenos Aires: Santiago Rueda editor.

" Rosanvallon, P. (2004). El pueblo inalcanzable. Historia de la representación democrática en Francia. México: Instituto Mora.

"Smith, P. (1974). Argentina and the Failure of Democracy. Conflict among Political Elites, 1904-1955. Madison: The University of Wisconsin Press. 